\title{
Word Stress in Saudi Najdi Arabic
}

\author{
Mohammad Al Amro \\ English Language Center, \\ Institute of Public Administration \\ P.O.BOX 205 \\ Riyadh, 11141 \\ Saudi Arabia
}

\begin{abstract}
Word stress patterns in Najdi Arabic have not received a great deal of attention even though Najdi Arabic could play a central role in the development of metrical theory. This study will provide a brief description of stress in Najdi Arabic dialect as well as Modern Standard Arabic. Beyond the analysis of word stress patterns, this paper will also attempt to deal with three important phenomena that affect stress, namely epenthesis/insertion, vowel shortening and consonant (the glottal stop) deletion. This paper shows that word stress in Najdi Arabic is predictable and heavy syllable carries stress.
\end{abstract}

Keywords: Najdi dialect, syllable, epenthesis, stress, penultimate, ultimate, antepenult

\section{Introduction}

Arabic language is a member of the Semitic language family which itself belongs to Afroasiatic phylum including Coptic, Berber, Chadic, Aramaic and Hebrew. It is the official language in twenty countries extending from North Africa to Western Asia. Arabic language is categorized into three types: Classical Arabic (the language of Holy Quran), Modern Standard Arabic and Arabic dialects. The lexical items and stylistics of Classical Arabic is different from those of Modern Standard Arabic with the exception of the morphology and syntax which remained unchanged over time (Watson,2007). Unlike other languages, no one in the Arab world are brought up using Modern Standard Arabic, but rather speaking their own dialects as their mother tongue. Modern standard Arabic is learned and mastered at schools. It is only used in formal written and spoken occasions (Watson, 2007).

The distinctive feature of modern standard Arabic language is that it is marked by "a limited vocalic system and a rich consonantal system" (Watson, 2007:1) such as guttural consonants which includes both the laryngeals. The three basic vowels are a,i,u ( three short vowels and three long forms “a:, i:, u:”) ( Aryan, 2001). Modern standard Arabic possess twenty-eight consonantal phonemes articulated in nine places of articulations (labiallabio-dental, inter-dental, dental alveolar, palatal, velar, uvular, pharynx-geal, larynx-geal).

Another distinguishing feature of Modern Standard Arabic language is their root and pattern morphology. The root is Arabic is a semantic abstraction comprising of two, three or four consonants from which words are derived through insertion a certain templatic patterns (Holes, 1995). For instance, from the root $\boldsymbol{K T B}$ meaning the lexical sense of 'writing', various words can be derived such as KiTaaB 'book', KaaTiB 'writer', maKTuuB 'written', and maKTaB 'office'. Nouns have masculine and feminine gender as well as plural and singular number, and in some cases dual (only preserved in Modern Standard Arabic but in Arabic dialects). Nouns are formed by internal vowel changes as in (Watson, 2007)

Singular plural gloss

Madrasat-un madaris-u school/schools

Adjectives are morphologically similar to nouns. They agree with noun subjects in gender and number, case, and definiteness. Additionally, they follow the nouns they describe as in the noun phrase (Brustad, 2000).

Al- baytu al-kabiru

The- house the-large

'the large house'

Modern Standard Arabic has a rich inflectional system of plurality forms for verbs and nouns as well as an inflectional system of case for nouns and verbs. The distinctive morphological features of Modern Standard Arabic are the following endings on nouns and verbs (Holes, 1995:41): 
a. A set of final short vowel endings suffixed to the noun to indicate case.

b. A set of final short vowel endings suffixed to the verb to indicate mood.

c. A final nasal ending $-\mathrm{n}$, (tanween), suffixed to the noun to indicate indefiniteness

These features are still used by Modern Standard Arabic but unfortunately they disappeared in Arabic dialects. Syntactically, the typical word order in Arabic is V (erb S(ubject) O (ject). However, the unmarked word order is changed depending on the dynamism of the verb (stative verbs usually occur after the nouns), text type (narratives usually use verb-initial clauses) and stylistics (Watson, 2007).

\section{Saudi Najdi Arabic}

Saudi Arabic dialects are classified into four groups: Najdi (tribes in the central of Saudi Arabia), Hijazi (tribes in the west), Assiri (tribes in the south), sharqawi (tribes in the east). Najdi Arabic is different from modern standard Arabic in terms of morphology, lexis as well as stylistics.

The phonological system of Najdi Arabic varies to some extent from Modern Standard Arabic. Najdi Arabic has thirty consonant sounds and the reference here to the phonological system. For instance, the voiceless affricate allophone [ts] of the phoneme [k] exist only in Najdi Arabic. Also, there are some sounds exist in Modern Standard Arabic but not used in Najdi Arabic. For instance, the voiced dental fricative is not pronounced in Najdi Arabic. This sound is only used by educated people in speech, lectures and news broadcasts. In term of vowel sounds, Najdi Arabic is similar to Modern Standard Arabic. It has three short vowels and three long ones.

\section{The syllabic structures of Modern Standard Arabic and Najdi Arabic}

Modern Standard Arabic has a limited range of syllable types compared to Najdi Arabic. Five syllables are attested in Modern Standard Arabic:CV, CVV, CVC, CVVC and CVCC. The syllable structure CV counts as a light syllable while CCV, CVV and CVC count as heavy syllables. The syllable structure CVVC and CVCC, on the other hand, are regarded as super-heavy syllables. Both light and heavy syllables appear word initially, medially and finally. Superheavy syllables, in contrast, occur at word end (Halpern, 2006).

Modern Standard Arabic does not permit CCV (double consonants or what it is called double onsets). Whenever double consonants are juxtaposed within the utterance, the first consonant acts as the coda of the first syllable and the second consonant represents the onset of the following syllable. For example, the $/ \mathrm{k} /$ in the word mak.tab is regarded as the coda and / $/$ / as the onset (or the beginning) of the second syllable (Mitchell,1990).

Najdi Saudi Arabic exhibits a various range of syllable structures. Seven syllables are shown in Najdi dialect: CV, CCV, CVV, CVC, CVVC, CVCVC and CVCC. The light syllable CV occurs in word initially, medially and finally. Similarly, the heavy syllable CVC occurs in all positions.

The heavy syllable CVV, unlike Modern Standard Arabic, does not occur in phonological word-final positions. In Najdi Arabic, the word ra.maa (throw) for instance, is pronounced as ra.ma. (a consonant followed by vowel CV) As for super-heavy syllables, they appear in utterance-final position.

Unlike speakers of Modern Standard Arabic, Najdi speakers sometimes insert a vowel in the syllable structure CVCC to split the final cluster depending on the Sonority Sequencing Principle which dictates that sonority must drop as we transit from one consonant to another. For instance, a vowel is epenthesized in the word (tifl "child") in Najdi dialect to break up the final cluster (tifil). The phoneme/ I / is chosen as the epenthetic vowel (Yavas, 2006). The consonant cluster [ $\mathrm{fl}$ ] has a sonority peak, rather than a sonority fall which makes Najdi native speaker insert a vowel [dIr]. Looking at a contradictory example in Arabic, a vowel is not inserted to split the consonant cluster in the lexicon (gird "monkey") because the coda clusters conform to the Sonority Sequencing Principle. That is the sequences [rd]is permitted whereas [fl] is not because the sonority level rises as we move for from /f/ to /l/. Unlike Modern Standard Arabic, Najdi Arabic permits initial consonant clusters (double onsets). For examples, fla.mu.hum"theirmovies", gla.mu.hum"their pens".

To the best of my knowledge, there are a few studies (such as Egyptian, Palestinian, Lebanese, Sudanese, and San'ani) that describe stress of Arabic dialects, which is perhaps due to the fact that many educated Arabs do not encourage research on the dialects for fear of damaging the status of Modern Standard Arabic especially when conducting written research on the colloquial. This study will provide a brief description of stress in Najdi Arabic dialect as well as Modern Standard Arabic. Beyond the analysis of stress patterns, this paper will also attempt to deal with three important phenomena that affect stress, namely epenthesis/insertion, vowel shortening and consonant (the glottal stop) deletion. 


\section{Najdi Arabic Stress}

Stress refers to the intensity with which the syllable is pronounced and it is used as a cover term for pitch, duration, and intensity (Hayes, 2009). To make the notions of stress clearer, there is a need to explain some terms. Within linguistics, in a word of four syllables, the names of the syllables are preantepenult- antepenultimate-penultimate-ultimate.

In English dissyllabic words, for instance, the default stress falls on the penultimate (e.g. agent) (from here on STRESS is shown in bold). In some exceptional cases, stress falls on the ultimate (e.g. appeal). Unlike English, Arabic stress is predictable. Thus English is not like Arabic which has "a surprisingly common stress rule" (Hayes, 2009: 284). That means one of the syllables is perceived as prominent and attracts stress. However, there are constraints on the location of the stress.

Arabic is also non-phonemic. That is, stress does not change the grammatical category nor does the meaning of the word (Halpern, 2006). In English, the noun (permit) is distinguished from the verb (permit) via stress. Even although Najdi dialect deviates from the Modern Standard Arabic and stresses words like (ka.ta.bat"she wrote") as (Ik.ta.bat "she wrote"), stress does not affect the meaning of the word.

Additionally, Arabic carries a primary stress like most languages. Every word possesses only one stress. A few languages such as English have a primary and a secondary stress. For instance, the English word (photographic) has two prominent syllables. The first one (pre-antepenult) is the secondary stress and the third (penultimate) is the primary stress (Yavas, 2006).

One major aspect of Arabic is that syllables, long or short, are pronounced. They do not disappear or get rendered because they are unstressed. If we look at English as a counter-example, we notice that the schwa /a / in absent is so weakened that it almost disappears. And this is what makes an Arab speaker pronounces an English word with an Arabic accent. For instance, [hi: went tu:sku:1] ( Kharma and Hajjaj, 1997).

Before delving into Najdi stress, a brief description of stress of Modern Standard Arabic would be useful to compare and understand stress patterns of Najdi dialect.

Stress in Modern Standard Arabic as well as Saudi dialects including Najdi dialect is governed by syllable weight. A heavy syllable attracts stress and light syllable does too in the absence of a heavy syllable. Stress rules of Modern Standard Arabic are as follows (Halpern, 2006):

1. Only one of the last three syllables is stressed. For example, mak.ta.ba.tun "library".

2. The stress falls on the ultimate syllable it is superheavy. For examples, ja.di:d " new", ri.jaal " men".

3. In monosyllabic words, the ultimate syllable attracts stress. For example, gad "already".

4. In dissyllabic words, stress falls on the penultimate. For examples, wa.lad"son", ka:.tib " writer".

5. In polysyllabic words, stress falls on the penultimate if it is heavy. For examples, Ja.di:.dun"new", ka.tab.tum"you write".

6. If the penultimate is light, stress moves to the antepenultimate. Foe examples, ka.li.ma "word", mak.ta.ba "library".

7. In longer words, the final syllable is not stressed if it is not superheavy. The syllable CVC is not stressed word finally. For examples,

Ka.li.ma.tun "word", ka.tab.tum "you wrote".

In fact, stress rules of Najdi dialect are slightly distinctive from Modern Standard Arabic.Stress Generalizations of Najdi Arabic are as a follows:

1. One of the last three syllables attracts the stress. For examples, ma.la.bis.hum"clothes", mid.rI.sih"school", kı.ta:.ba.tuh"his writing"

2. Stress falls on the final syllable if it is super-heavy (CVCC, CVVC, CVVCC, CVCVC). In most Arabic dialects, superheavy syllables surface at the end of the words. For examples, mu.sa.ha.ma:t "contributions" ; 1r.sa.nı.ya:t" linguistics".

3. In a two syllable word, the penultimate syllable bears the stress. For example,

ba.na "he built"

4. In polysyllabic words, stress falls on the antepenultimate if the penultimate is light. In the following example, the penultimate is light and thus the penultimate attracts stress. 
mak.ta.buh"his office".

Looking at another example taken from Modern Standard Arabic (yak.tub.na"they(fem) write") and Najdi Arabic dialect (yak.tr.bn "they (fem) write), it is noticed that stress in Najdi Arabic falls on the antepenult because the penultimate is light. Stress, on the other hand, in Modern Standard Arabic is on the penultimate since it is heavy.

In the Egyptian dialect, the penultimate always bears stress even if the antepenult is heavy and this is a clear indication that Najdi dialect is closer to the Modern Standard Arabic than other dialects such as the Egyptian dialect. For examples, mit.nar.fI.za "angry", mad.ra.sa. Even though the penultimate is light'fi, ra' and the antepenult is heavy, stress does not fall on the antepenult but on the penultimate (Buell, 2003). Using the same example, the antepenult carries stress in mad.ra.sah, rather than the penultimate which indicates that stress prominence is assigned to heavy syllable.

5. The CVV syllables attract stress. For example,

kI. ta:.ba:.tuh "his writings".

Contrary to the CVV syllable, final CVC syllables do not attract stress although they are regarded as heavy syllables. For example, mid.ri.sih"school”.

There are phenomena affecting the location of stress. Epenthesis, vowel shortening or consonant (the glottal stop) deletion, affects the syllable structure and thus it can change the position of stress.

\section{Epenthesis}

Epenthesis of a vowel is exclusively allotted to word initially. For examples,

Table 1. Vowel epenthesis in Modern Standard Arabic and Najdi Arabic

\begin{tabular}{|l|l|}
\hline Stress of Modern standard Arabic & Najdi Arabic \\
\hline Ka.ta.bat "she wrote" & ik.ta.bat "she wrote" \\
\hline Ka.ta.bu "they wrote" & ik.ta.bu "they wrote" \\
\hline
\end{tabular}

In Najdi Arabic, stress, as mentioned before, falls on the antepenultimate if the penultimate is light. But in these examples, the penultimate attracts stress and this change in stress is attributed to the vowel insertion. Stress in ka.ta.bat (she wrote) moves to Ik.ta.bu in Najdi Arabic ( table 1).

\section{Glottal Deletion}

Glottal deletion affects the syllable structure and thus alters the location of stress. For examples,

Table 2. Glottal deletion in Modern Standard Arabic and Najdi Arabic

\begin{tabular}{|l|l|}
\hline Stress of Modern Standard Arabic & Najdi Arabic \\
\hline ?al.ki:m.ya:? " chemistry" & ?al.ki:m.ya " chemistry" \\
\hline ?al.fi:z.ya:? " physics" & ?al.fiz.ya " physics" \\
\hline ?al.ga.da:? "lunch" & ?al/ga.da " lunch" \\
\hline ?al.sa.ma:? "sky" & ?al.sa.ma. \\
\hline
\end{tabular}

In the above examples, stress in Modern Standard is on the ultimate since it is a heavy syllable. In Najdi dialect, stress moves to the penultimate as in "?al.ki:m.ya" because the syllable becomes light. In the last three examples (?al.fiz.ya, ?al/ga.da and ?al.sa.ma), it is noticed that stress moves to the antepenultimate since the penultimate and the ultimate are categorized as light ( table 2).

\section{Contrastive Vowel Length (Vowel shortening)}

The long vowel in Modern Standard becomes short in some cases in Najdi dialect and this of course changes the position of stress. Examples showing (a) the contrastive vowel length in final position are presented in the following table, stress here fall on the penultimate. Stress moves, for instance, from ma:tora in the word ram:(throw) (table 3).

Table 3. Vowel shortening in the final position in Najdi Arabic

\begin{tabular}{|l|l|}
\hline Modern Standard Arabic & NajdiArabic \\
\hline ra.ma: "he threw" & ra.ma "he threw" \\
\hline ra.ha: "he went" & Rah "he went" \\
\hline
\end{tabular}

(b)Contrastive vowel length in the medial position: 
In the following examples, the position of stress in Najdi Arabic is not affected by the vowel shortening in the medial position and it still conforms to stress rules. In the example of Najdi Arabic Ji.ra "purchase", the penultimate fi. attracts stress. Similarly, stress in the word fi:.rain Modern Standard Arabic is on the penultimate (Table 4).

This indicates that vowel shortening in Najdi Arabic in medial position is different from vowel shortening in the final position which could play a role in stress position in Najdi Arabic as it is shown in table 3.

Table 4. Vowel shortening in the medial position in Najdi Arabic

\begin{tabular}{|l|l|l|}
\hline Modern Standard Arabic & NajdiArabic & \\
\hline Ji:.ra:? "purchase (n)" & Ji.ra “purchase (n)" & \\
\hline ga:.la "he said" & gal "he said" & \\
\hline la:.ma "he blamed" & lam "he blames" & \\
\hline
\end{tabular}

\section{Loan Words:}

Even in loan words from English, Najdi dialect follow the same stress patterns with these loans. For examples,

Table 5. Loan words in Najdi Arabic

\begin{tabular}{|l|l|}
\hline English & Najdi Arabic \\
\hline Television & ta.la.viz.yu:n \\
\hline Mobile & mo.ba.yaal \\
\hline
\end{tabular}

It is noticeable from the above examples that the syllabic structure alters the stress location. These examples display that Arabic stress, including Najdi Arabic, is predictable and follows a certain pattern, compared to English. Stress in both examples is on the ultimate since it is super-heavy(CVVC). Stress here is on yu:n and yaal in ta.la.viz.yu:nand mo.ba.yaal, respectively.

\section{Conclusion}

Having established the syllable structure and syllabification in Modern Standard Arabic and Najdi Arabic, the paper has discussed the word stress systems in these two varieties. The focus on word stress in Najdi Arabic has been for two reasons. First, phonological literature lacks studies on Najdi word stress. Second, Najdi Arabic poses more challenges for a theory about word stress than other Saudi dialects particularly in terms of the privilege of its own syllable structures as well as its effect by syllable repair processes such as vowel epenthesis, glottal deletion and vowel shortening. Stress system in Najdi Arabic is predictable and possesses common stress rule. It invariably assigns stress to the heavy syllables and it has only one primary stress.

\section{References}

Aryan, R. (2001). Arabic Roots. M.A Dissertation . Dominguez Hills, CA, USA: California State University. Brustad, K. (2000). The Syntax of Spoken Arabic. Washington: Georgetown University Press. Buell, L. (1996). A Footless, Constraint-Based Analysis of Stress in Cairene Arabic. Unpublished Article.

Halpern, J. (2006). Word Stress and Vowel Neutralization in Modern Standard Arabic. The CJK Dictionary Institute. Hayes, B. (2009). Introductory Phonology. Blackwell Publishing.

Holes, D. (1995). Modern Arabic: Structures, Functions and Varieties. New York: Longman.

Kharma, N. \&Hajjaj, A. (1997). Errors in English among Arabic Speakers. York Press.

Jong, K.D., \&Zawaydeh, B.A. (1999). Stress, Duration, and Intonation in Arabic Word-Level Prosody. Journal of Phonetics, 27, 3-22.

Mitchell, T. (1990). Pronouncing Arabic. Oxford: Oxford University Press.

Yavas, M. (2006). Applied English Phonology. Blackwell Publishing.

Watson, J. C. (2007). The Phonology and Morphology of Arabic. Oxford, New york: Oxford University Press. 